\title{
Toxocariasis in Britain as Revealed by Skin Sensitivity Tests
}

\author{
R. A. WISEMAN,* L.R.C.P., M.R.C.S., D.T.M.\&H., D.OBST.R.C.o.G. ; A. W. WOODRUFF,* M.D., PH.D., F.R.C.P., F.R.C.P.ED.
}

Brit. med. F., 1968, 1, 677-678

Infection of human beings with the dog nematode Toxocara canis occurs, it is thought, in approximately $2 \%$ of persons in southern England, and is especially likely to be found where there is a close association with dogs, particularly puppies. In experimental or proved infections the most prominent signs and symptoms have been shown to be persistent eosinophilia, hepatomegaly, and recurrent fever or malaise (Beaver et al., 1952 ; Smith and Beaver, 1953; Snyder, 1961). Pulmonary infiltration with cough, dyspnoea, or bronchospasm has been observed in suspected cases (Beaver, 1962), encephalitis with convulsions may occur during the acute phase of infection (Brain and Allan, 1964), and the larval stages of $T$. canis have been identifed in a number of eyes enucleated owing to suspicion of malignancy in the presence of a retinal granuloma (Wilder, 1950 ; Irvine and Irvine, 1959 ; Ashton, 1960 ; Woodruff et al., 1961).

The recent development of an intradermal skin test (Woodruff and Thacker, 1964) which was shown not to give rise to a significant number of false-positive reactions or to crosspositive reactions in patients with non-toxocaral helminthiasis, but which produced positive reactions in patients with proved toxocariasis (to be reported later) and in animals experimentally infected with $T$. canis (Wiseman and Woodruff, 1967), has demonstrated that skin sensitivity to the antigen injected assists in the diagnosis of toxocaral infection, past or present, in those patients in whom eye enucleation or liver biopsy is unnecessary or impracticable.

This paper reports an investigation of the incidence of toxocariasis as shown by the sensitivity to the intradermal skin test in patients in whom clinical suspicion of toxocaral infection was strongly aroused by one or more of the signs and symptoms outlined above.

\section{Materials and Procedure}

The method of preparing the intradermal skin test has been previously reported (Woodruff and Thacker, 1964); it consists of the injection of $0.1 \mathrm{ml}$. of a $1 / 1,000$ solution of saline extract of desiccated powdered adult $T$. canis worm. The antigen was injected intradermally into the left forearm of the patient in each case, and the weal produced was measured at the time of injection and again after 20 minutes.

The skin test was performed on 189 patients for whom requests for antigen were received at the Central Public Health Laboratory, Colindale, and who were suspected of having toxocariasis because of unexplained eosinophilia, choroidoretinitis, hepatomegaly, recurrent fevers, past or present asthma, or general ill-health with anorexia and irritability.

\section{Results}

Of the 189 patients tested $24(12.7 \%)$ gave a positive result as shown by doubling of the initial area of the weal in 20 minutes. Many of them were investigated for a persistent or marked eosinophilia, in association with one or more of the syndromes \footnotetext{
- Department of Clinical Tropical Medicine, London School of Hygiene
and Tropical Medicine, London N.W.1.
}

listed in the Table. Many of the patients with eosinophilia also had a marked leucocytosis.

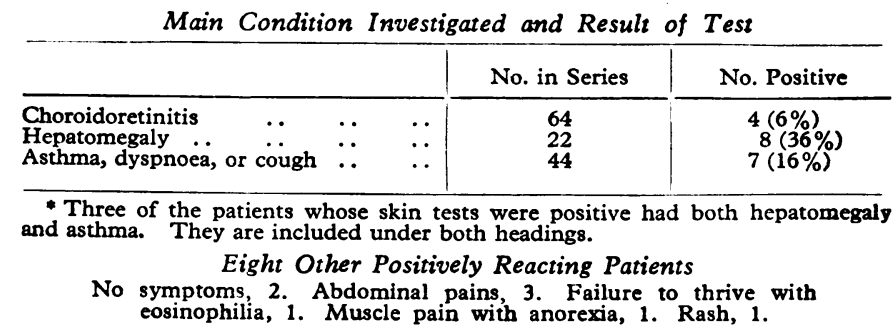

In 17 of the 24 patients with positive skin tests a history of pica or close association with dogs was obtained. One other patient, a boy of 2 years, was reported as living in insanitary conditions, four other patients denied such an association, and in two there was no record.

\section{Comment}

A number of observations of experimental infections with $T$. canis in animals and suspected toxocariasis in human beings have been recorded (Beaver et al., 1952; Smith and Beaver, 1953 ; Shoho, 1955 ; Beaver, 1956 ; Chaudhuri and Saha, 1959), and, while persistent eosinophilia, hepatomegaly, choroiditis, and pulmonary infiltration are mentioned together or separately as indicating possible toxocaral infection, there are many other causative agents that can give rise to these signs. Thus in investigating a group of patients with those lesions, though a number of these will be due to causes other than toxocariasis, a certain percentage will be due to toxocariasis, and the level of this percentage will depend on the criteria of selection for entry into the series. It is also likely that a large proportion of those with toxocariasis will have had an association with dogs, cats, or dirt-eating.

A previous survey (Woodruff and Thacker, 1964) in which more stringent criteria of selection were used showed that of 35 patients in whom toxocariasis was suspected on clinical grounds $11(31.4 \%)$ were positive reactors; this finding may be compared with the $12.7 \%$ of 189 in the present survey whose skin reaction was positive. The $12.7 \%$ of positive reactors may also be compared with the expected $2.1 \%$ of positive reactors in apparently healthy persons (Woodruff et al., 1966), and it indicates that the lesions in these cases were almost certainly due to toxocariasis. Further support is given by the fact that $17(71 \%)$ out of the 24 positive reactors had a history of insanitary conditions, pica, or close association with dogs or cats.

Many of the patients were selected for investigation because of persistent or high eosinophilia, and therefore the finding that $20(90 \%)$ out of the 22 positive reactors for whom all data were available had an eosinophilia is to be expected. Beaver (1962) noted that in approximately $80 \%$ of patients with toxocaral infection the eosinophils represented more than $50 \%$ of the total leucocytes, and that the absolute eosinophil counts were about $20,000 / \mathrm{cu}$. mm. in more than half the cases. In this series, however, the eosinophil counts did not attain such 
high levels, though this is possibly accounted for by the presence of lighter infections (Smith and Beaver, 1953). Only seven out of 20 positive reactors for whom all the data were available had absolute eosinophil counts above $5,000 / \mathrm{cu} . \mathrm{mm}$., and in only five patients was the eosinophilia recorded as being above $10,000 / \mathrm{cu}$. $\mathrm{mm}$.

There were 22 patients with hepatomegaly in the series, and $8(36 \%)$ were positive reactors to the skin test. Beaver (1956) recorded that hepatomegaly was usually seen in the earlier stages of infection; he also found that it was present in a majority of patients (Beaver, 1962). Of the eight positive reactors six were under the age of 10 years, a finding which suggests that toxocariasis may be an important cause of hepatomegaly in young children in the United Kingdom.

The four patients classified under the heading of choroidoretinitis with positive skin tests had the following lesions: (1) "non-specific uveitis"; (2) " carly retinitis, settled without treatment-toxoplasma serology negative"; (3) "retinal swelling with white fibrous streaks round the macula-toxoplasma dye test negative"; and (4) "granulomatous iridocyclitis." Further information on these four patients with regard to a history of pica or of association with dogs, or to their eosinophil counts, was unfortunately incomplete, but it is of interest to note that the second patient's lesion had settled without treatment, possibly indicative of a light infection in which the small number of helminthic larvae present had caused only a minimal reaction.

Of the 44 patients in the series with pulmonary signs or symptoms seven $(16 \%)$ gave a positive reaction to the intradermal test. This may be compared with the observation of Synder (1961), who noted cough or wheezing in $20 \%$ of his toxocariasis patients. All seven of the positive reactors in this series had a considerable eosinophilia (one patient had 55,760 eosinophils/cu. mm., another 10,045/cu. mm., and a third $8,200 / \mathrm{cu}$. mm.), and four out of these seven patients gave a history of pica or recent association with young puppies.

It is concluded that since $12.7 \%$ of 189 patients in which infection with $T$. canis was suspected on clinical grounds gave a positive reaction to the toxocara intradermal test, toxocaral infection probably represents a serious hazard to health in the United Kingdom. The majority $(71 \%)$ of these positive cases gave a history of pica or close contact with dogs ; the danger of this was pointed out in a previous report (Woodruff and Thacker, 1964), which established that $20.7 \%$ of London dogs had a parasitologically confirmed infection with $T$. canis. Further, the $12.7 \%$ of positive reactors in the present series most probably represents a small fraction of the actual amount of transmission of $T$. canis which is occurring, since many cases with light infections will be asymptomatic or lead to undiagnosed malaise and ill-health.

\section{Summary}

Infection of human beings with the dog nematode Toxocara canis can be diagnosed by an intradermal skin sensitivity test, $T$. canis being used as antigen. A survey using this test in patients with clinically suspected toxocariasis showed that 24 of $189(12.7 \%)$ gave positive reactions, and 17 of these 24 had a history of close association with dogs or pica. Ninety per cent. of the positive reactors had been referred because of persistent eosinophilia; of 22 patients investigated for hepatomegaly 8 gave positive reactions and of these 6 were under the age of 10 years, suggesting that toxocaral infection may be an important cause of hepatomegaly in children in the Linited Kingdom. Seven positive reactors were found in the group of 44 patients investigated for dyspnoea or bronchospasm, and 4 positives in the 64 investigated for choroidoretinitis. The high incidence found in this survey suggests that toxocaral infection probably represents a serious hazard to health in the U.K.

We are indebted to Dr. C. M. Patricia Bradstreet, of the Central Public Health Laboratory, Colindale, for her great help in the preparation and organization of this survey, and to many general practitioners who participated. The work was also made possible by the receipt of an M.R.C. grant to one of us (R. A. W.), which is here acknowledged.

\section{REFERENCES}

Ashton, N. (1960). Brit. 7. Ophthal., 44, 129.

Beaver, P. C. (1956) Exp. Parasit., 5, 587.

Beaver, P. C. (1962). Bull. Soc. Path. exot., 55, 555

Beaver, P. C., Snyder, C. H., Carrera, G. M., Dent, J. H., and Lafferty, J. W. (1952). Pediatrics, 9, 7.

Brain, Lord, and Allan, B (1964). Lancet, 1, 1355.

Brain, Lord, and Allan, B. (1964). Lancet, 1, 1355. 493

Irvine, W. C., and Irvine, A. R. (1959). Amer. F. Ophthal., 47, No. 5 part 2 , p. 185 .

part 2, p. 185. Rev. ibér. Parasit., special vol., p. 927.

Shoho, C. (1955). Rev. iber. Parasit., special vol., p. 927.
Smith, M. H. D., and Beaver, P. C. (1953). Pediatrics, 12, 491.

Smith, M. H. D., and Beaver, P. C. (1953).
Snyder, C. H. (1961). Peliatrics, 28, 85

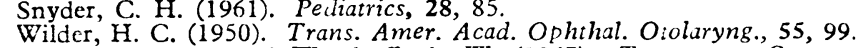

Wiseman, R. A., and Woodruff, A. W. (1967). Trans. roy. Soc. trop. Med. Hyg., 61, 827.

Woodruff, A. W., Ashton, N., and Stott, G. J. (1961). Trans. roy. Soc. trop. Med. Hyg., 55, 13 .

Woodruff, A. W., Thacker, C. K. (1964). Trans. roy. Soc. trop. Med Hyg., 1, $100 \mathrm{i}$.

Woodruft, A. W., Bisseru, B., and Bowe, J. C. (1966). Brit. med. F., 1, 